\title{
Tendencies and prospects in the digital economy development in Russia
}

\author{
Yana Nikonova ${ }^{1, *}$, and Alexey Dementiev ${ }^{1}$ \\ ${ }^{1}$ Siberian State University of Railway Engineering, 630049, 191 Dusi Kovalchuk str., Novosibirsk, \\ Russia
}

\begin{abstract}
The paper opens a series of publications within the framework of a project designed to investigate the impact of digitalization of the Russian economy on the qualitative change in its structure and long-term opportunities.
\end{abstract}

\section{Introduction}

The electronic and information revolution that has been taking place in the economy for more than four decades has had a significant impact on the transformation of economic relations. Economic relations in the digital economy are complicated in terms of their subject-object side, when they are supplemented by electronic and digital algorithms. The specificity of transformation of economic relations is in the fact that the processes of information reproduction become dominant in comparison with other types of economic activity, and also have a significant influence on them. New digital technologies expand opportunities and can serve as a new source of universal global economic growth.

The share of digital economy by now is about $22.5 \%$ of the global economy, and it still has huge potential for further development. According to the report of the Digital McKinsey expert group, published in 2017, "the digital economy entered a decisive phase, and every second inhabitant of the Earth connected to the Internet" [1]. It is expected that through the use of digital technologies, the global economy will create up to $\$ 2$ trillion of additional products by 2020 [9].

Until now, the attention of researchers has been mainly focused on the evolution of the global economy under the impact of digital technologies and problems and prospects for the development of the global digital economy [13], as well as electronic fraud, digital piracy and other forms of shadow digital consumption [8]. The concept of the formation of digital economy in Russia began to be established only in 2017 with the adoption of the program on creating conditions for the transition of the country to the digital economy named "Digital Economy of the Russian Federation".

The purpose of this article is to study trends and prospects for the development of digital economy in Russia, as well as to identify the potential of the Russian Federation in international cooperation in the digital economy.

\footnotetext{
*Corresponding author: ya_shka@ngs.ru
} 


\section{Materials and methods}

To achieve this goal, the authors use qualitative research methods, including content analysis of documents and empirical generalization.

\section{Literature Review}

The term "digital economy" was first used in 1995. However, the opinions on who is its author are different. According to one point of view, the term was introduced by Nicholas Negroponte, the American computer scientist, who highlighted the advantages of the new economy, such as a lack of weight of products, virtuality, low demand for raw materials and the possibility of instant global migration [12].

According to the second point of view, the appearance of the term "digital economy" is associated with the publication of Don Tapscott's book "The Digital Economy" in 1994 [14], in which he describes how digital technologies and business strategies transform not only business processes, but also ways of creating products and services and the market itself. Don Tapscott defines digital economy as an economy based on information computer technology.

At the global level, the idea of digital economy was voiced in the World Development Report 2016 "Digital Dividends" by the World Bank. Under the digital economy the World Bank experts understand the system of economic, social and cultural relations based on the use of digital information and communication technologies.

The development of modern concepts of the digital economy is shown in the Figure 1. The very first concept of the development of digital economy was based on the need to expand Internet access for millions of consumers.

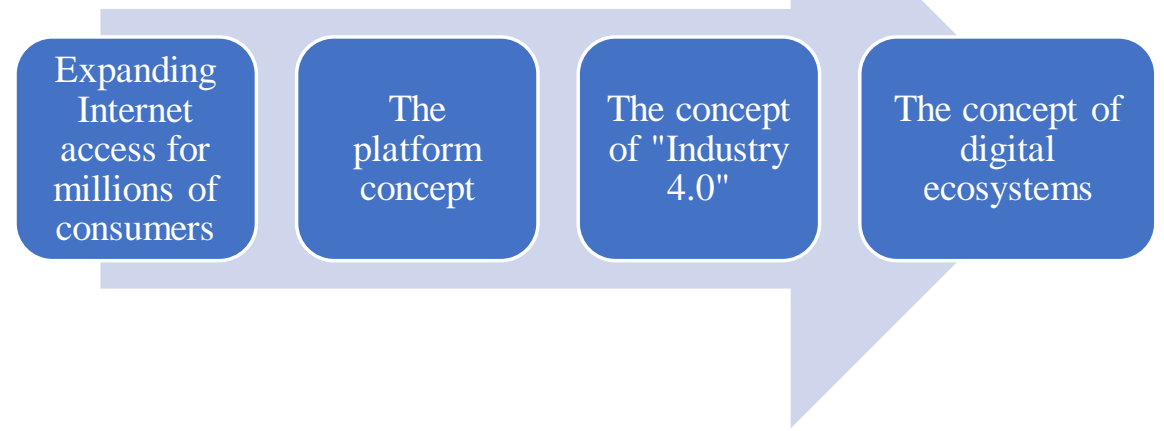

Fig. 1. Modern concepts of the development of the digital economy.

The platform concept was formed in the trade and logistics sector. It is based on the creation of new business models, characteristic only for the digital economy - the digital platforms, whose main task is to provide business and the population with specific services in order to coordinate activities of various market participants.

The concept of "Industry 4.0" became the. driver of digitalization of the industrial sector. This concept is also called the Fourth industrial revolution and caused by a change in the principles of organization of production processes based on the deep integration of information technology (Figure 2).

The result of the Fourth industrial revolution will be the space of digital ecosystems, where in the interaction of stakeholders, collective network competencies will be formed. 
Existing approaches to the definition of the concept of "digital ecosystem" are significantly different.

V. Shendrik considers digital ecosystem in a narrow sense as a set of devices, services and technologies, and believes that Micrisoft, Apple, and Google are the creators of it [4].

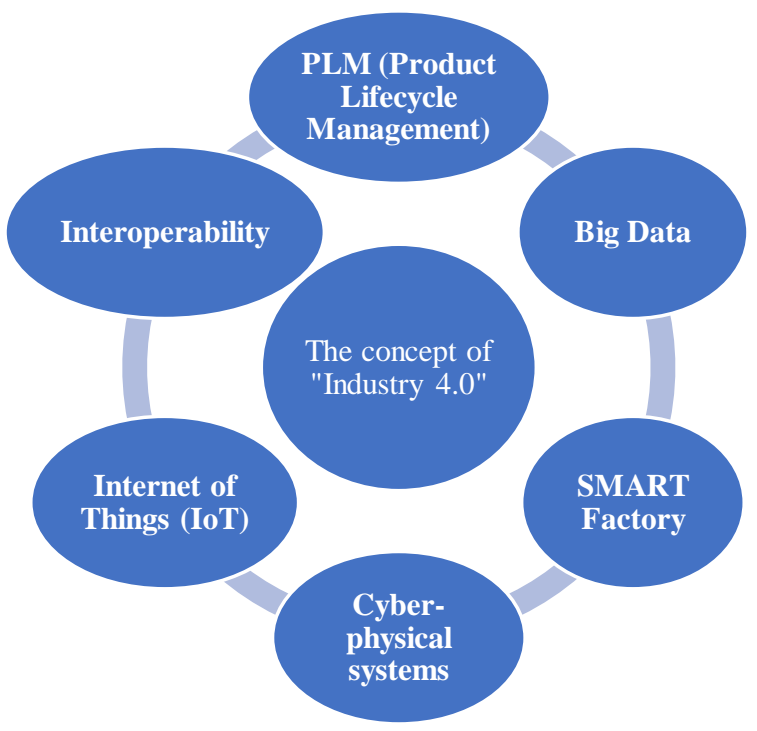

Fig. 2. Subsystems of the concept "Industry 4.0".

F. Nachira, P. Dini, and A.A. Nicolai believe that it is formed through the convergence of three networks: the IT network, social network, and knowledge sharing network [10]. They introduce the concept of digital business ecosystems, which provides continuous innovation, access to knowledge, global added value chains, specific services, adaptation of new technologies, and adoption of new business models [11]. As noted by E. Chang and M. West, the ecosystem is defined as the domain of a clustered environment in which all participants are weakly connected, respecting their own benefit and conserving the environment. With the development of information and communication technologies, people began to live simultaneously in the digital and ecological environments, that is, in the double environment [6]. Thus, under digital ecosystem, they mean a clustered environment that includes its biological, economic and digital kinds and the natural environment.

\section{Results}

Under the digital economy, in this study we will understand the system of relations based on the use of digital information and communication technologies (Figure 3).

In our opinion, if the ecosystem is a biological system of living organisms that exchange substances and energy among themselves and their environment, the digital ecosystem is a representation of the socio-technical system in the form of a set of computer programs with distributed interaction and mutual use by agents for the exchange of knowledge in the conditions of evolutionary self-development.

To assess the development of digital economy, the Fletcher School at Tufts University, in partnership with MasterCard, introduced the Digital Evolution Index (DEI) of 2017 [7]. DEI 2017 is a comprehensive assessment of the development of digital economy in 60 countries, based on data, combining more than 100 different indicators. The resulting structure reflects both the state and speed of digital evolution and determines the implications 
for investment, innovation and policy priorities. DEI 2017 also highlights the changing nature of the risks created by the constant dependence on digital technologies.

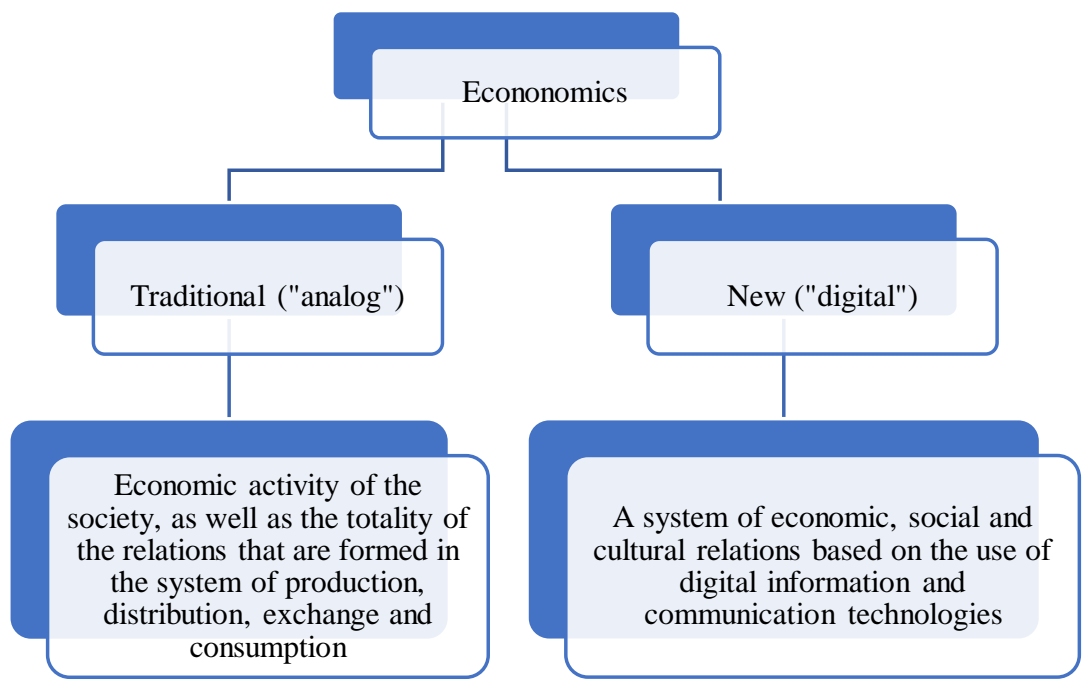

Fig. 3. Comparison of approaches to the definition of a traditional "analog" and a new "digital" economy.

The DEI structure divides 60 countries into Stand Outs, Stall Outs, Break Outs and Watch Outs. Three countries are defined as winners even in the Stand Out segment: Singapore, New Zealand and the UAE. Each of them has a unique strategy based on politics, and a narrative that can be considered by other countries as worthy of imitation or acceptance. The countries of Northern Europe and Switzerland are at the top of the DEI 2017. China, again, tops the list of countries in terms of the rate of change in its digital evolution. Russia ranks the $39^{\text {th }}$ in the ranking of the digital economies of the world, and India, China, the Philippines and Malaysia are next to it.

The share of digital economy in the GDP of all countries is steadily growing. Thus, the share of digital economy in the GDP of developed countries over the past five years has increased from $4.3 \%$ to $5.5 \%$, and in the GDP of developing countries - from $3.6 \%$ to $4.9 \%$. According to The Boston Consulting Group, the share of digital economy in the GDP of the G20 countries for the period from 2010 to 2016 increased from $4.1 \%$ to $5.3 \%$. Great Britain is the global leader in this indicator - $12.4 \%$ [5].

Less than twenty years ago, all countries were at the stage of creating digital economy. However, now the level of the digital economy development in the countries of the world differs significantly. The Boston Consulting Group specialists divided all countries of the world into 5 groups according to the level of welfare and digitization of the economy (Figure $5)$.

Despite the fact that this sphere is relatively new, even now nine companies control more than $90 \%$ of the entire digital economy of the world and receive more than $90 \%$ of all profits: Microsoft, Google, Apple, Facebook, Amazon and four Chinese companies.

From 2010 to 2016, the market capitalization of Alphabet, Facebook, Amazon, Microsoft and Apple (AFAMA) increased by $\$ 2.3$ trillion. On the contrary, the cost of 28 non-AFAMA companies making up the Dow Jones Industrial index rose by $\$ 1.7$ trillion, seven times less than in AFAMA. At the same time in China, Alibaba and Tencent are among the ten most valuable companies of the world, and together with Baidu they collectively cost almost 1 trillion dollars. 


\section{I group}

The group of leaders includes countries with the highest percentage of "digitization" of economic operations, and a high level of

These are six countries: South Korea, Denmark, Great Britain, Sweden, Norway, Netherlands. technologies used for such "digitization".

\section{II group}

The main group of countries includes the majority of developed economies of the world.
These are, for example, Germany, the United States, Japan, and the EU countries.

\section{III group}

The third group covers countries with a high level of well-being (GDP per capita), but with lower rates of "digitization" of operations.
These are the countries of the Middle East, primarily the UAE and Saudi Arabia.

\section{IV group}

The fourth group is "beginning leaders". In these countries, the level of development of digital operations is higher than the level of development of the economy.
The brightest representative of this group is China.

\section{V group}

The group of "laggards" in the development of digital economy.

All other countries.

Fig. 4. Classification of countries by the level of the digital economy development. 
In 2016, the analysts of International Data Corporation published a study, according to which the global costs for digital transformation will grow annually by $16.8 \%$, and by 2019 will reach the level of $\$ 2.1$ trillion.

The consulting company Accenture published a forecast that by 2020 the GDP of developed countries will grow by digitization by $1.8 \%$, and developing countries - by $3.4 \%$

According to the forecasts of The Boston Consulting Group, the digital economy in the world will reach $\$ 16$ trillion by 2035 .

Thus, the achievement of a competitive advantage on the global digital arena has become a key priority for the governments, businesses and citizens who are seeking inclusion and relevance in this global marketplace. It is also clear that the momentum, innovation and trust play a crucial role when countries strive to improve their digital development.

\section{Discussions}

In the digital economy, new patterns and trends appear that did not exist in the "traditional" economy.

The formation of a new market of Internet services and products of services that penetrate all spheres of the economy and change the economy as a whole is the first distinctive feature of the digital economy.

Globalization of economic processes on the basis of strengthening integration of various spheres of the economy in connection with the formation of the world electronic network is the fundamental trend and the principle of development of modern economy.

The next distinctive feature of the digital economy is the decrease in the value and physical content of material factors of social production. First of all, we are talking about the increasing importance of the information and digital component in the costs of production. The value and competitiveness of companies are largely determined by the intangible component, such as knowledge, ideas, and artificial intelligence, which ensure the core strategic competencies of modern companies.

The change in the importance of the key factors of production - the factor of time and distance - is another distinguishing feature of the digital economy. The price of "time" as a category of social production is incommensurably increasing. The ability of a firm to make transactions in the online mode determines the success of this firm on the market. On the other hand, the role of distance and geographic location of counterparties in transactions is being significantly reduced. Sellers and buyers can interact almost instantly using the global electronic network.

The human capital and the intellect of workers becomes the leading factor of social production. This makes it necessary to apply new forms and methods of personnel management aimed at maximizing the use of human potential.

The principle of accelerating economic growth is another distinguishing feature of digital economy. Distribution and adaptation of products in the sphere of production and circulation is greatly accelerated thanks to the electronic network, since information about products and changes on the markets spreads almost instantly.

Direct interconnection of market participants leads to a change in the institution of mediation in the digital economy. Traditional distributors and agents are no longer necessary. However, in the conditions of rapid growth of information volumes, there is a need for a new kind of mediation - information one.

The merging of the buying and selling and marketing processes into a single process is another distinctive feature of the digital economy: in the online mode, the gap between the search for the desired product and its purchase disappears.

Thus, the emergence and development of global electronic networks and digital technologies radically changes the content, correlation and importance of the following 
concepts in the new economy: material and non-material distance and time, utility and cost, competition and consumer preferences, human capital of new relations of producers and consumers, marketing and sales technologies, and so on.

\section{Conclusions}

In the digital economy, new patterns and trends appear that did not exist in the "traditional" economy. Along with the emergence of new patterns and trends, the content of traditional economic postulates changes, which in combination and interconnection with digital technologies manifest themselves in a new way.

Thus, the emergence and development of global electronic networks and digital technologies radically changes the content, correlation and significance of the following concepts in the new economy: material and non-material distance and time, utility and cost, competition and consumer preferences, human capital of new relations of manufacturers and consumers, marketing and sales technologies, etc.

\section{References}

1. Cifrovaya Rossiya: novaya real'nost, otchet 2017 , iyul (https://www.mckinsey.com/russia/our-insights/ru-ru).

2. Cifrovizaciya: istoriya, perspektivy, cifrovye ehkonomiki Rossii i mira (http://www.uppro.ru/library/strategy/tendencii/cyfrovizaciya-trend.html)

3. T. V. Avdeenko, A. A. Aletdinova, Nauchno-Tekhnicheskie Vedomosti SPbGPU Ekonomicheskie Nauki, 10, 1 (2017)

4. V. S. Hendrik, Cifrovaya Ekosistema (http://shendrik.net/2016/01/28).

5. Boston Consulting Group, New digital hegemony (https://www.bcg.com/publications/ 2017/strategy-globalization-new-digital-world-hegemony-harmony-aspx).

6. E. Chang, M. West, Digital ecosystems: a next generation of the collaborative environment (iiWAS, 2006)

7. Digital planet 2017: how competitiveness and trust in digital economies vary across the world (https://sites.tufts.edu/digitalplanet/executive-summary)

8. L. Gaspareniene, R. Remeikiene, V. Navickas, Procedia Economics and Finance, 39 (2016)

9. M. Knickrehm, B. Berthon, P. Daugherty, Digital disruption: the growth multiplier, Accenture (https://www.accenture.com/_acnmedia/PDF-4/Accenture-Strategy-DigitalDisruptionGrowth-Multiplier.pdf)

10. F. Nachira, P. Dini, A. A. Nicolai, Digital business ecosystems (European Commission, Bruxelles, 2007)

11. F. Nachira, P. Dini, A. A. Nicolai, Digital business ecosystems. (http://www.digitalecosystems.org/events/2006.06-sardegna/nachira-sarde-gnaict.pdf)

12. N. Negroponte, Being digital (Knopf, 1995)

13. OECD Digital Economy Outlook 2017 (http://www.oecd.org/sti/oecd-digital-economyoutlook-2017-9789264276284-en.htm)

14. D. Tapscott, The digital economy: promise and peril in the age of networked intelligence (McGraw-Hill, 1994) 